\title{
Acute Upper Limb Ischemia: Prompt Surgery and Long-Term Anticoagulation Prevent Limb Loss and Debilitation
}

\author{
Patrick Harnarayan' \\ Shariful Islam ${ }^{2}$ \\ Dave Harnanan' \\ Vinoo Bheem ${ }^{2}$ \\ Steve Budhooram ${ }^{3}$ \\ 'Department of Clinical Surgical Sciences, \\ University of The West Indies, \\ St. Augustine, Trinidad \&Tobago; \\ ${ }^{2}$ Department of Surgery, San Fernando \\ General \& Teaching Hospitals, San \\ Fernando, Trinidad \&Tobago; ${ }^{3}$ The Surgi- \\ Med Clinic, San Fernando, Trinidad \& \\ Tobago
}

Background: Acute upper limb ischemia is an uncommon clinical manifestation of thromboembolism seen predominantly in patients with atrial fibrillation. Treatment can be by conservative or surgical means but the consensus is that after conservative treatment, symptoms still persist. In this series, an attempt was made at limb preservation and return to functional capacity by early surgery in all patients diagnosed with acute limb ischemia.

Methods: Patients referred with upper limb ischemia (22) were stratified into non-acute (6) treated with anticoagulation alone and those with acute ischemia. Sixteen (16) patients, age range 30-92 years (median 62.4 years) comprising mainly females (13), had clinical evidence of severe ischemia and underwent immediate brachial embolectomy with postoperative anticoagulation.

Results: Sixteen patients underwent 20 embolectomies with immediate reperfusion of limbs and relief of symptoms. Two patients had two re-operations each due to recurrent symptoms but both recovered with good outcome, one going on to have an axillary-radial bypass. There was no limb disability nor limb loss, but one postoperative mortality. All other patients were seen at their 1-year review and at 5 years, eleven out of 15 patients were still alive with most resuming an active lifestyle and some returning to work.

Conclusion: Good outcomes were obtained in this series in both the short and long term. Despite one mortality, there was no limb loss nor disability in a mainly elderly population. Prompt surgery and meticulous long-term anticoagulation reduced complications and improved limb salvage rates ensuring that patients had a good quality of life after surgery.

Keywords: acute-ischemia, prompt-surgery, anticoagulation, limb-salvage

\section{Introduction}

The relationship between atrial fibrillation (AF) and thromboembolism has been well recognized as far back as 1936 when the presence of increased levels of AF in patients with embolism was noted. ${ }^{1}$ Warren and Linton then observed that of all the patients in their study with peripheral embolism, a high percentage $(65 \%)$ of patients had emboli arising from the atrium because of $\mathrm{AF}^{2}$ In comparison to acute lower limb ischemia, acute upper limb ischemia (AULI) is relatively uncommon, ${ }^{3,4}$ but can be associated with significant morbidity including debility, limb loss, and mortality. In order to diminish these complications, the authors encouraged early identification and referral of patients with severe acute upper limb ischemia. This was augmented with prompt surgery, therapeutic levels of
Correspondence: Patrick Harnarayan Email patrick_harnarayan@hotmil.com 
postoperative anticoagulation, and close monitoring of patients. Herein we present our experience with a small series of sixteen (16) patients seen at our institution.

\section{Patients and Materials}

\section{Patients}

Our patients were selected from a prospectively kept database which included patients referred for acutely ischemic upper limbs over a period of sixteen (16) years. In all, twenty-two (22) patients were identified with upper limb ischemia but sixteen (16) were considered acute, severe, and limb-threatening. The majority of patients (14) presented with cold fingers and hands, twelve (12) presented with paraesthesia or numbness, ten (10) with cyanosis of one or more finger tips, ten (10) with pain, and eight (8) with pallor of the fingers or hand. Four (4) patients presented with muscular compromise, two (2) with paralysis, and two (2) with weakness of the hand [Table 1].

Of the sixteen (16) patients who were referred, thirteen (13) were females, three (3) males, with an age range of 32 to 92 years and median age of 62.4 years. The age, ethnicity, and premorbid history of all patients including their known risk factors were recorded [Table 1]. Ten (10) were of Afro-Caribbean descent and the remaining six (6) were of Asian East Indian origin.
The clinical presentation and the duration of symptoms of patients were also noted [Table 2], with the commonest duration of symptoms being twenty-four (24) hours, seen in $50 \%$ of patients (8), but three (3) patients presented in less than twenty-four (24) hours, two presented after fortyeight (48) hours, two longer than this (72 hours and 96 hours), and one after a week.

\section{Patient Analyses}

Of the sixteen (16) patients who presented, ten (10) had absent or reduced radial pulses at presentation with seven (7) recorded as having atrial fibrillation (AF), four (4) of whom had a past history of AF [Table 2]. Almost all the patients of this sub-group were elderly females (ages 77, 79,89 ) but the one young female (aged 56) had a history of valvular heart disease likely of rheumatic origin. Two had pacemakers and one had ECG changes suggestive of a very recent myocardial infarct. In all, six (6) patients had a cardiac history including three (3) with previous myocardial infarcts but eleven (11) patients were hypertensive, three (3) diabetic, and three (3) had previous cerebrovascular accidents (CVA). One of the patients was hyperthyroid, five (5) were being treated for hyperlipidemia, two were current smokers, two ex-smokers, and one a known end stage renal failure (ESRD) patient. One patient was treated for cervical carcinoma, and another had a previous deep vein thrombosis (DVT) and a strong family history of

Table I Patient Demographics, Risk Factors, Antiplatelet/Anticoagulant Medication, Compliance and Medical History

\begin{tabular}{|c|c|c|c|c|c|c|c|c|c|c|c|}
\hline Patient & Age & Gender & Pulse & $\mathrm{H} / \mathrm{o} \mathrm{AF}$ & Cardiac Dis & HTN & Smoker & $\mathbf{A} / \mathbf{P}$ & $A / C$ & Compliance & $\begin{array}{l}\text { Current/Past } \\
\text { History }\end{array}$ \\
\hline 1. & 79 & $\mathrm{~F}$ & $\mathrm{AF}$ & Yes & - & Yes & Ex & - & Warfarin & Poor & Previous Embolectomy \\
\hline 2. & 79 & $\mathrm{~F}$ & $\downarrow$ & Pacemaker & IHD, BBB & Yes & - & Aspirin & Warfarin & Stopped** & Complete heart block \\
\hline 3. & 89 & $\mathrm{~F}$ & $\mathrm{AF}$ & Yes & - & Yes & - & - & - & 一 & Intestinal Obstruction \\
\hline 4. & 56 & $\mathrm{~F}$ & $\mathrm{AF}$ & Yes & Mitral stenosis & Yes & - & 一 & 一 & 一 & Rheumatic disease \\
\hline 5. & 47 & $\mathrm{~F}$ & - & - & Murmur & Yes & - & 一 & 一- & 一- & $\mathrm{BMI}>30$ \\
\hline 6. & 58 & $\mathrm{~F}$ & $\mathrm{AF}$ & - & - & - & - & 一 & - & 一 & Active Malignancy \\
\hline 7. & 77 & $M$ & - & - & - & Yes & Yes & 一 & 一 & 一 & Stroke, $\uparrow$ Lipids, Diabetic \\
\hline 8. & 43 & $\mathrm{~F}$ & - & - & - & Yes & - & 一- & 一- & 一 & BMI=28, $\uparrow$ Lipids \\
\hline 9. & 55 & $\mathrm{~F}$ & - & Pacemaker & $\mathrm{IHD}$ & Yes & - & 一 & 一 & 一- & MI, Stroke, Diabetic \\
\hline 10. & 32 & M & - & - & - & - & Yes & 一 & - & 一- & Hyperthyroid-no Rx \\
\hline II. & 57 & M & - & - & $\mathrm{IHD}$ & Yes & - & Aspirin & - & 一 & ESRD on dialysis \\
\hline 12. & 48 & $\mathrm{~F}$ & - & - & - & - & - & Aspirin & - & - & $\uparrow$ Lipids, DVT \\
\hline 13 & 39 & $\mathrm{~F}$ & - & - & $\mathrm{IHD}$ & Yes & - & Aspirin & - & - & $\uparrow$ Lipids, OCP \\
\hline 14. & 92 & $\mathrm{~F}$ & $\mathrm{AF}$ & - & - & - & - & - & - & 一 & $\uparrow$ Lipid, Hypothyroid \\
\hline 15 & 81 & $\mathrm{~F}$ & $\mathrm{AF}$ & Yes & - & Yes & - & 一 & Warfarin & Low & $\mathrm{AF}$ \\
\hline 16. & 77 & $\mathrm{~F}$ & $\mathrm{AF}$ & - & - & Yes & - & 一 & 一 & 一 & Stroke \\
\hline
\end{tabular}

Note: **Stopped due to gastrointestinal bleeding.

Abbreviations: AF, atrial fibrillation; $\downarrow$, bradycardia; H/o, History of; Cardiac Dis, cardiac disease; IHD, ischemic heart disease; BBB, bundle branch block; HTN, hypertensive; A/P, antiplatelet drug; A/C, anticoagulant drugs; BMI, body mass index; $\uparrow$ Lipids, hyperlipidemia; MI, myocardial infarct; ESRD, end stage renal disease; DVT, deep vein thrombosis; OCP, oral contraceptive pill. 
Table 2 Clinical Presentation, Arteriotomy, Anesthesia, and Immediate Outcome

\begin{tabular}{|c|c|c|c|c|c|c|c|c|}
\hline \multirow[t]{2}{*}{ Patient } & \multicolumn{5}{|c|}{ Clinical Presentation } & \multicolumn{3}{|c|}{ Surgical Intervention } \\
\hline & Pain & Paraesthesia & Cyanosis & Cold & Duration & Arteriotomy & Anesthesia & Outcome \\
\hline I & - & $\sqrt{ }$ & - & $\sqrt{ }$ & $24 \mathrm{hrs}$ & Longitudinal & GA & Good flow-pulses \\
\hline 2 & $\sqrt{ }$ & $\sqrt{ }$ & - & - & $24 \mathrm{hrs}$ & Longitudinal & LA & Good flow-pulses \\
\hline 3 & - & $\sqrt{ }$ & $\sqrt{ }$ & $\sqrt{ }$ & $12 \mathrm{hrs}$ & Longitudinal & LA & Good flow-pulses \\
\hline 4 & $\sqrt{ }$ & - & - & $\sqrt{ }$ & $12-24 \mathrm{hrs}$ & Transverse & BB & Good flow-pulses \\
\hline 5 & - & $\sqrt{ }$ & - & $\sqrt{ }$ & $48 \mathrm{hrs}$ & Transverse & LA & Good flow-pulses \\
\hline 6 & - & $\sqrt{ }$ & $\sqrt{ }$ & $\sqrt{ }$ & $48 \mathrm{hrs}$ & Transverse & LA* & 2 re-explorations \\
\hline 7 & $\sqrt{ }$ & $\sqrt{ }$ & $\sqrt{ }$ & $\sqrt{ }$ & $24 \mathrm{hrs}$ & Transverse & LA & Good flow-pulses \\
\hline 8 & $\sqrt{ }$ & $\sqrt{ }$ & $\sqrt{ }$ & $\sqrt{ }$ & $96 \mathrm{hrs}$ & Oblique & $\mathrm{LA}^{*}$ & 2 re-explorations \\
\hline 9 & $\sqrt{ }$ & - & $\sqrt{ }$ & $\sqrt{ }$ & $72 \mathrm{hrs}$ & Oblique & LA & Good flow-fasciotomy \\
\hline 10 & $\sqrt{ }$ & $\sqrt{ }$ & $\sqrt{ }$ & - & $24 \mathrm{hrs}$ & Oblique & LA & Flow-pulses \\
\hline II & $\sqrt{ }$ & $\sqrt{ }$ & $\sqrt{ }$ & $\sqrt{ }$ & $8 \mathrm{hrs}$ & Oblique & LA* & Flow-pulses \\
\hline 12 & - & $\sqrt{ }$ & $\sqrt{ }$ & $\sqrt{ }$ & $120 \mathrm{hrs}$ & Oblique & LA & Good flow-pulses \\
\hline 13 & $\sqrt{ }$ & $\sqrt{ }$ & $\sqrt{ }$ & - & $24 \mathrm{hrs}$ & Oblique & LA & Good flow-pulses \\
\hline 14 & - & $\sqrt{ }$ & $\sqrt{ }$ & - & $24 \mathrm{hrs}$ & Oblique & LA & Good flow-pulses \\
\hline 15 & $\sqrt{ }$ & - & - & $\sqrt{ }$ & $24 \mathrm{hrs}$ & Oblique & LA & Good flow-pulses \\
\hline 16 & $\sqrt{ }$ & $\sqrt{ }$ & - & - & $24 \mathrm{hrs}$ & Oblique & GA & Good flow-pulses \\
\hline $\mathrm{T}$ & $10 / 16$ & $13 / 16$ & $10 / 16$ & $11 / 16$ & & & & \\
\hline
\end{tabular}

Abbreviations: LA, local anesthesia; LA*, local anesthesia with sedation; BB, brachial block.

atherosclerosis (mother had a femoral to plantar bypass) but no other risks factors. Another young patient (thirtynine) had hyperlipidemia, was on the oral contraceptive pill (OCP), and had a previous history of a myocardial infarct.

This population was primarily an elderly one with eight (8) out of the sixteen (16) being 70 and over, six (6) between the ages of 40 and 60 years, and only 2 below the age of 40. Cardiac disease made up the major risk factors with hypertension, ischemic heart disease, and valvular heart disease being major contributors but smokers and those with a history of diabetes were also at risk of thromboembolism. Patients with previous cerebrovascular attacks (CVAs), myocardial infarcts, and malignancies also appeared to be at risk of arterial embolism. Four patients with ischemic heart disease were on aspirin at the time of thromboembolism whilst three were placed on warfarin due to $\mathrm{AF}$. One stopped taking the medication because of a moderate gastrointestinal bleed, one was noncompliant, and the other weakly compliant.

\section{Imaging}

All patients, after clinical examination, were initially investigated using a Hand-Held Doppler (HHD), and absent pulses on the affected side was taken as a hard sign of acute limb ischemia with further investigation by color duplex interrogation. One patient who had an inconclusive duplex scan had imaging by a Magnetic Resonance Angiogram (MRA) which demonstrated an acute occlusive embolus.

Patients had a 12-lead ECG and echocardiography but one pitfall was the inability to access an echocardiogram as an emergency investigation, prior to surgery. This was done the following day by the in-service cardiology team.

\section{Decision to Treat}

Twenty-two (22) patients with ischemic upper limbs were referred for further management. Sixteen (16) of these were considered to be severe and limb threatening due to acute presentation with loss of arterial perfusion, sensory loss, or muscular involvement. Prolonged ischemia can lead to severe debility, limb loss, and mortality however there is evidence that surgery is superior to anticoagulation alone, ${ }^{3}$ especially in patients presenting within the first 12 hours. ${ }^{3}$ Early surgery was our treatment of choice with postoperative anticoagulation to decrease risk of further embolization.

\section{Technique}

Surgery was done mainly under local anesthesia, but regional and general anesthesia were used for two (2) cases each [Table 2]. The surgical approach was to access the brachial bifurcation. A longitudinal arteriotomy was initially used on the brachial artery but this was refined first to a transverse incision then to an oblique arteriotomy, from 
medial inferiorly to lateral superiorly which is believed to reduce the chance of vessel stenosis [Table 2]. This was positioned at the bifurcation to give access to both end arteries [Figure 1- Brachial artery, devoid of blood flow prior to embolectomy].

A size \#2 embolectomy catheter was gently used to remove thrombus by passing it up the brachial artery and down both the radial and ulnar arteries to retrieve embolic material which was not always sent for microbiologic and histological confirmation. The endpoint was a well perfused hand with palpable radial and ulnar pulses [Figure 2-Filling of the brachial artery, pre-arteriotomy site (yellow arrow) and post-arteriotomy site (blue arrow) after embolectomy]. A vein patch was used if the procedure was a repeat surgical procedure or where stenosis at arteriotomy site was envisaged. Fasciotomies were used in two cases, one at time of surgery and one postoperatively after development of a hematoma.

\section{Results and Outcomes}

Twenty (20) emergency procedures were done on 16 patients, 18 were done by a vascular surgeon, and two (2) by surgeons with vascular experience. All patients who had surgery immediately benefitted from the thrombus removal with revascularization of the hand including the digits. Two patients had re-operations (two) for recurrence of ischemia whilst still at hospital, one resolved and one needed an arterial bypass from axillary to proximal radial artery to reverse the ischemia. In addition to these there was one wound hematoma, one delayed wound closure but no wound infections.

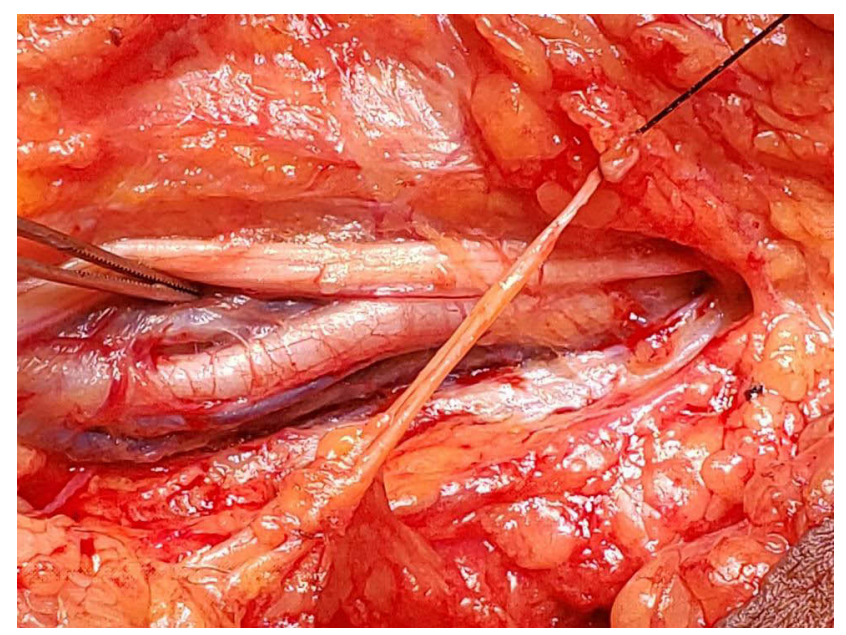

Figure I Brachial artery, devoid of blood flow prior to embolectomy.

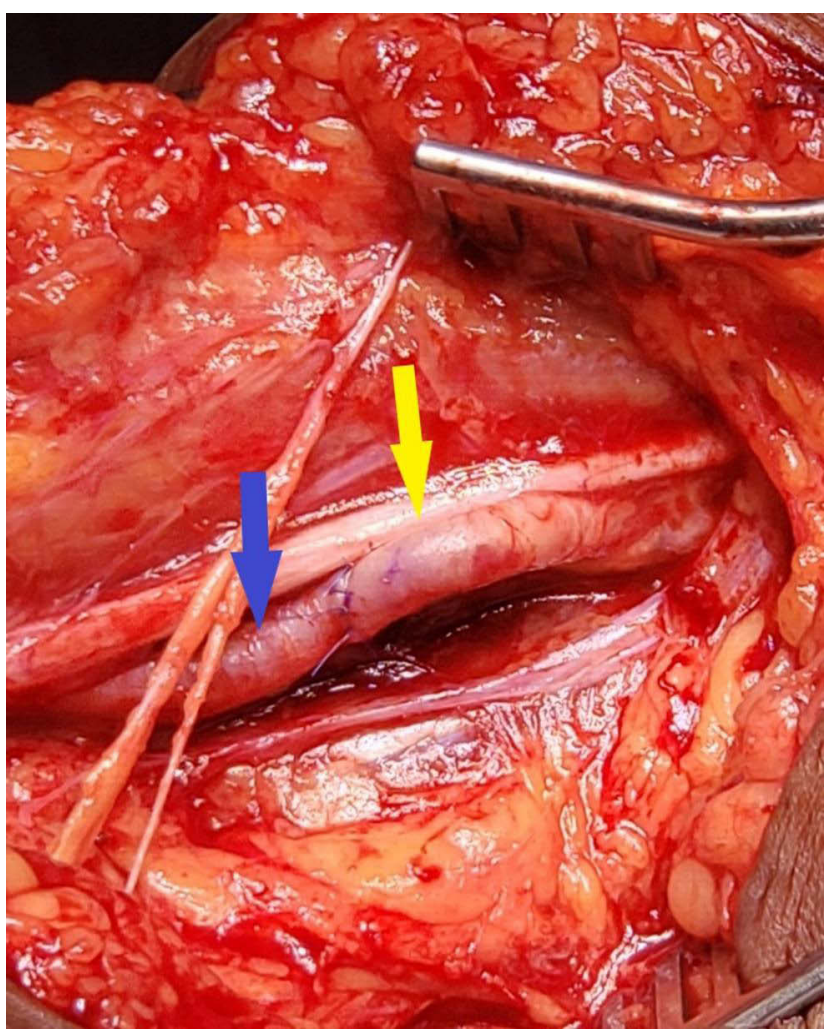

Figure 2 Filling of the brachial artery showing pre-arteriotomy site (yellow arrow), post-arteriotomy site (blue arrow) and oblique arteriotomy in between, after embolectomy.

Functional outcome stratified by time of presentation was analyzed. Most patients presented within 24 hours (11) but 5 presented after this time (48 hours, 48 hours, 72 hours, 96 hours and 1 week). The two patients who had reoperations presented late (48 hours and 96 hours) as well as the patient with delayed fasciotomy (72 hours), whilst the other presenting at 48 hours had difficulty with achieving anticoagulation initially taking several days to achieve a good endpoint. The other case presenting at 1 week was a young patient with mild symptoms with a reasonable perfusion but had no major complications. In general, the later the presentation, the greater the complication.

There was one postoperative (1) mortality in an elderly patient who had a laparotomy for intestinal obstruction and who was noted to have an ischemic hand following laparotomy. She was treated surgically since the ischemic changes were advanced and these were reversed by brachial embolectomy. This patient initially recovered following surgery but developed acute renal failure and never recovered, surviving only five (5) days post-surgery. 
Fifteen (15) of the sixteen (16) patients were alive one year after surgery with eleven out of fifteen being followed-up in clinic five (5) years later. Beyond five (5) years, five more passed away, so sixteen (16) years after the study started, six (6) patients were alive, four actively working, with two mobile pensioners.

\section{Discussion}

The most common cause of upper limb embolism is of cardiac origin and the brachial artery is the most common site at which the embolus lodges. ${ }^{5}$ Acute upper limb ischemia (AULI) is less common than the lower limb, accounting for approximately $10-15 \%$ of all peripheral emboli. ${ }^{3}$ The relative risk of thromboembolectomy among patients with AF (compared to the baseline population) was 7.5 for men and 9.3 for women. ${ }^{6}$

When patients with AF are analyzed, the risk of thromboembolism is increased in those with hypertension, myocardial infarct, heart failure, and stroke. ${ }^{6}$ Other factors include protruding fixed aortic plaques which if $>5 \mathrm{~mm}$ thickness $^{7}$ constituted a significant risk of embolization. Disrupted mobile aortic plaques were also a major risk factor for systemic embolism in the elderly, as well as intra-cardiac lesions, malignant tumors, proximal aneurysms of upper limb arteries, external compression from cervical ribs, arteritis, fibromuscular dysplasia and hypercoagulable states. ${ }^{1}$

The patients with AULI typically present with paraesthesia, pain, pallor or cyanosis and cold fingers and hand but may progress to ischemia of the fingers, hand, and the forearm. Absence or reduction of the radial and ulnar pulses are common findings but in many cases there is also an absent brachial pulse. ${ }^{8}$ Although the diagnosis is clinical, it can be confirmed by duplex scan, but routine arteriography is usually not warranted unless presentation is atypical and signs are equivocal. ${ }^{9}$

Patients who present late tend to have poorer outcomes $^{3,10}$ and there is an increased risk of amputation in patients with a delayed diagnosis and treatment. ${ }^{11,12}$ The success of treatment and good outcomes depend on prompt early surgery ${ }^{13}$ and good postoperative anticoagulation ${ }^{14}$ both associated with increased salvage of the upper limb. ${ }^{15}$ Functional problems were more likely in patients with a longer duration of symptoms. ${ }^{16}$

Conservative management can be considered since it avoids surgery and may have good outcomes. ${ }^{17}$ However, there is a lack of good quality evidence for non-surgical treatment and poor functional outcomes were more often seen after conservative treatment. ${ }^{18}$ Thrombolysis is also an option for treatment of upper limb vascular occlusions being locally effective, ${ }^{19}$ but up to $33 \%$ of treated patients have complications with the risk of hemorrhage, cerebrovascular events, and even death with its usage. ${ }^{20}$

Once the diagnosis has been made, early surgery is the best option available. ${ }^{11}$ Brachial embolectomy is the treatment of choice for patients with AULI due to thromboembolism. ${ }^{21}$ Embolectomy has good outcomes, as in our series, with rapid revascularization, ${ }^{22}$ good functional results, ${ }^{23}$ and low complication rates. ${ }^{15}$ Reoperation rates for occlusion vary from $5-9 \%{ }^{5}$ and can be due to technical failures, ${ }^{24}$ re-embolization, ${ }^{25}$ injury to the intima during the initial surgery ${ }^{26}$ and poor anticoagulation postoperatively. ${ }^{27}$ Surgery under local anesthesia is safe, poses little threat to the patient's life, and results are better than conservative treatment with even those patients having repeat embolectomies getting good outcomes. ${ }^{24,28}$

Complications reflect the condition of the patient at the time of surgery. The risk of a stroke after surgery is significant, with a large percentage of patients (19.1\%) having a first stroke after embolectomy, ${ }^{1}$ ten percent $(10 \%)$ of these having the stroke on the date of admission. ${ }^{1}$ The cumulative risk of a stroke at 30 days was $4.7 \%$ for men and $6.0 \%$ for women. ${ }^{1}$ Upper limb amputation varied from $2.2 \%{ }^{29}$ to $18 \%{ }^{15}$,with women having the higher risk of amputation.

The overall risk of mortality is higher than in the general population with the risk of death being three to eleven (3-11) times higher. ${ }^{29}$ In this population, patients are elderly with significant co-existing disease, ${ }^{30}$ so even though the longterm outcome appears to be poor ${ }^{31}$ many patients die from unrelated causes. ${ }^{5,9}$ However the 1-year survival is good ${ }^{28,32}$ as in our series where the 1-year survival was over $90 \%$, the 5-year survival $73 \%$, with no limb-loss nor disability and return to near-normal activities with a good quality of life.

\section{Conclusion}

Surgery without delay should be considered in cases of acute upper limb ischemia once there are signs of severe, progressive ischemia. There are surgical risks in this population but the possibility of debilitation, limb-loss, and mortality seen with delayed or conservative treatment usually tilts the balance in favor of surgery.

The overall results of surgery are better than conservative treatment, with prompt intervention and meticulous anticoagulation, the short- and long-term outcomes in our series were good. Patients had no hospital readmissions, no limb loss, and an acceptable quality of life following surgery. 


\section{Consent}

Informed consent was obtained from all the patients involved in this series.

Institutional Review was conducted and approval granted by the Hospital/Health Authority's Bioethics Committee. This study was conducted in accordance with The Declaration of Helsinki.

\section{Author Contributions}

All authors contributed to data analysis, drafting or revising the article, have agreed on the journal to which the article will be submitted, gave final approval of the version to be published, and agree to be accountable for all aspects of the work.

\section{Disclosure}

The authors report no conflicts of interest in this work.

\section{References}

1. Andersen LV, Lip GY, Lindholt JS, Frost L. Upper limb arterial thromboembolism: a systematic review on incidence, risk factors, and prognosis, including a meta-analysis of risk-modifying drugs. J Thromb Haemost. 2013;11(5):836-844. doi:10.1111/jth.12181

2. Warren R, Linton RR. The treatment of arterial embolism. $N$ Engl J Med. 1948;238:421-429. doi:10.1056/NEJM194803252381301

3. Quraishy MS, Cawthorn SJ, Giddings AEB. -Critical ischemia of the upper limb. J R Soc Med. 85:1992269-1992272.

4. Welling RE, Cranley JJ, Krause RJ, Hafner CD. Obliterative arterial disease of the upper extremity. Arch Surg. 1981;116:1593-1595. doi:10.1001/archsurg.1981.01380240073012

5. Rudarakanchana N, Chesire NJ. Acute upper limb ischemia, Chapter 5.1, Section 5, vascular disease of the upper limb. In: Thompson M, editor. Oxford Textbook of Vascular Surgery. Oxford University Press; 2016.

6. Andersen LV, Mortensen LS, Lip GY, et al. Atrial fibrillation and upper limb thromboembolectomy: a national cohort study. J Thromb Haemost. 2011;Sep(9):1738-1743. doi:10.1111/j.1538-7836.2011.04435.x

7. Tenenbaum A, Fisman EZ, Schneiderman J. Disrupted mobile aortic plaques are a major risk factor for systemic embolism in the elderly. Cardiology. 1998;89:246-251. doi:10.1159/000006795

8. Ling Bang S, Nalachandran S. Upper limb ischemia-a single centre experience. Ann Acad Med Singapore. 2009;38:891-893.

9. Lin G, Kais H, Negri M, Chen D, Peer A, Halevy A.Surgery for acute arterial emboli to the arm. Harefuah. 1994;126(5):245-247, 304.

10. Kofoed H, Hansen HJ. Arterial embolism in the upper limb. Acta Chir Scand Supp. 1976;472:113-115.

11. Rapp JH, Reilly LM, Goldstone J, Krupski WC, Ehrenfield WK, Stoney RJ. Ischemia of the upper extremity: significance of proximal arterial disease. Am J Surg. 1986;152(1):12-16. doi:10.1016/00029610(86)90161-3

12. Davies MG, O’Malley K, Feeley M, Colgan MP, Moore DJ, Shanik G. Upper limb embolus: a timely diagnosis. Ann Vasc Surg. 1991;5:85-87. doi:10.1007/BF02021785
13. Vrtik L, Zernoviky F, Kubis J, Simo JD, Matis P.Arterial embolisms in the extremities. Rozhl Chir. 2001;80(9):465-469.

14. Cupka I, Bruncak P, Pelc J, Berek P, Kovacs V.Acute arterial occlusions of the upper extremities. Rozhl Chir. 2003;82 (3):157-160.

15. Eyers P, Earnshaw JJ. Acute non-traumatic arm ischaemia. Br J Surg. 1998;85:1340-1346. doi:10.1046/j.1365-2168.1998.00884.x

16. Bae M, Chung SW, Lee CW, Choi J, Song S, Kim SP. Upper limb ischemia: clinical experience of acute and chronic upper limb ischemia in a single center. Korean J Thorac Cardiovasc Surg. 2015;48 (4):246-251.

17. Jane E, Turner H, Loh A, Howard A. Conservative approach to acute upper limb ischemia. Vascular Dis Manag. 2010;7(11): E219-E222.

18. Wong VW, Major MR, Higgins JP, et al. Nonoperative management of acute upper limb ischemia. Hand (NY). 2016;11 (2):131-143.

19. Michaels JA, Torrie EP, Galland RB. The treatment of upper limb vascular occlusions using intra-arterial thrombolysis. Eur $J$ Vasc Surg. 1993;7(6):744-746. doi:10.1016/S0950-821X(05) 80731-5

20. Deguara J, Ali T, Modarai B, Burnand KG. Upper limb ischemia: 20 years' experience from a single center. Vascular. 2005;13(2):84-91. doi:10.1258/rsmvasc.13.2.84

21. Wirsing P, Andriopoulos A, Botticher R. Arterial embolectomies in the upper extremity after acute occlusion. Report on 79 cases. J Cardiovasc Surg (Torino). 1983;24(1):40-42.

22. Hernandez-Richter T, Angele MK, Helmberger T, Jauch KW, Lauterjung L, Schildberg FW. Acute ischemia of the upper extremity: long-term results following thrombembolectomy with the Fogarty catheter. Langenbecks Arch Surg. 2001;386(4):261-266. doi:10. 1007/s004230100224

23. Fan LH, Ye JR, Fu WG, et al. Surgical treatment of acute embolism of the upper extremity. Zhonghua Wai Ke Za Zhi. 2003;41(1):50-51.

24. Vohra R, Lieberman DP. Arterial emboli to arm. J R Coll Surg Edinb. 1991;36(2):83-85.

25. Kretz JG, Weiss E, Limuris A, Eisenmann B, Greff D, Kieny R. Arterial emboli of the upper extremity: a persisting problem. J Cardiovasc Surg (Torino). 1984;25:233-235.

26. Staudacher M, Bohm C, End A, Haberzettl C, Muller MR, Vodrazka M. Embolic occlusion of arteries of the upper extremity. Vasa. 1991;20(4):358-364.

27. Karr G, Broe PJ, Bouchier-Hayes DJ. Upper limb emboli. A review of 55 patients managed surgically. J Cardiovasc Surg (Torino). 1989;30(2):165-168.

28. Baird RJ, Lajos TZ. Emboli to the arm. Ann Surg. 1964;160:905-909. doi:10.1097/00000658-196411000-00020

29. Andersen LV, Mortensen LS, Lindholt JS, Faergeman O, Henneberg EW, Frost L. Upper-limb thrombo-embolectomy: national cohort study in Denmark. Eur $J$ Vasc Endovasc Surg. 2010;40:628-634. doi:10.1016/j.ejvs.2010.06.009

30. Sultan S, Evoy D, Eldin AS, Eldeeb M, Elmehairy N. Atraumatic acute upper limb ischemia: a series of 64 patients in a Middle East tertiary vascular centre and literature review. Vasc Surg. 2001;35 (3):181-197. doi:10.1177/153857440103500305

31. Licht PB, Balezantis T, Wolff B. Long-term outcome following thromboembolectomy in the upper extremity. Eur J Vasc Endovasc Surg. 2004;28(5):508-512. doi:10.1016/j.ejvs.2004.08.007

32. Magishi K, Izumi Y, Shimizu N. Short- and long-term outcomes of acute upper extremity arterial thromboembolism. Ann Thorac Cardiovasc Surg. 2010;16(1):31-34. PMID: 20190707. 


\section{Publish your work in this journal}

Vascular Health and Risk Management is an international, peerreviewed journal of therapeutics and risk management, focusing on concise rapid reporting of clinical studies on the processes involved in the maintenance of vascular health; the monitoring, prevention and treatment of vascular disease and its sequelae; and the involvement of metabolic disorders, particularly diabetes. This journal is indexed on PubMed Central and MedLine. The manuscript management system is completely online and includes a very quick and fair peerreview system, which is all easy to use. Visit http://www.dovepress. com/testimonials.php to read real quotes from published authors. 